\title{
Editorial:
}

\section{Continuous steel box girders and reinforced concrete structures in the Main Bridge Project of Hong Kong-Zhuhai-Macao Bridge}

Qiang JING

Hong Kong-Zhuhai-Macao Bridge Authority, Zhuhai 519060, China E-mail: jq@hzmbo.com

https://doi.org/10.1631/jzus.A1900645

As the longest sea-crossing highway bridge in the world, the 55-km Hong Kong-Zhuhai-Macao Bridge (HZMB) directly connects Hong Kong, Zhuhai, and Macao, which are three cities in China that are geographically close but separated by the Pearl River Estuary (PRE). The construction of the project lasted from January 2011 to February 2018 and was finally opened to traffic in October 2018 (Gao et al., 2016; Zhu et al., 2019). The total investment of the project was 126.9 billion CNY (about 18.03 billion USD). As shown in Fig. 1, the HZMB consists of three main sections: the Main Bridge (29.6 $\mathrm{km})$ in the middle, the Hong Kong Link Road (12 km) in the east, and the Zhuhai Link Road (13.4 km) in the west. As the longest part, the estimated cost of the Main Bridge was 38.1 billion CNY (about 5.41 billion USD). The actual cost, however, was 51.1 billion CNY (about 7.26 billion USD).

The Main Bridge Project is a bridge-islandtunnel structure, which includes $22.9-\mathrm{km}$ sea-crossing bridges and a $6.7-\mathrm{km}$ immersed tunnel that runs between two artificial islands ( $\mathrm{Su}, 2005)$. The highway class of the project is a dual 3-lane expressway with a design speed of $100 \mathrm{~km} / \mathrm{h}$. The bridges have a standard deck width of $33.1 \mathrm{~m}$ and a height clearance of $5.1 \mathrm{~m}$. For wind resistance consideration, the design standard wind speed is $47.6 \mathrm{~m} / \mathrm{s}$ within a design return period of 120 years. The return period of seismic

(D) ORCID: Qiang JING, https://orcid.org/0000-0002-1599-2423 (c) Zhejiang University and Springer-Verlag GmbH Germany, part of Springer Nature 2020 fortification is 120 years for the working states, 1200 years for bridges over navigable waters in limit state, 600 years for bridges over non-navigable waters in limit state, and 2400 years for structural integrity states (Hussain et al., 2011; Meng et al., 2014a; Zhu et al., 2019). The design service life of the project is 120 years (Zhang and Zhu, 2012, 2018).

To cross over the navigable waters, the Main Bridge Project uses three cable-stayed bridges to allow shipping traffic to pass underneath, including the Jiuzhou Channel Bridge (693 m), the Jianghai Channel Bridge (994 m), and the Qingzhou Channel Bridge $(1150 \mathrm{~m})$. The decks of the bridges are steelconcrete composite box girders, and the Qingzhou Channel Bridge has the longest single-span of $458 \mathrm{~m}$. As shown in Fig. 2, towers with different shapes were used on the three bridges, i.e. the Jianghai Channel Bridge adopts three steel dolphin-shape towers, and the Qingzhou Channel Bridge adopts two concrete towers with steel bracing in the shape of a traditional Chinese Knot. Meanwhile, on the non-navigable waters, considering the water gets deeper from the west side of the PRE to the east side, the Main Bridge Project uses 85-m steel-concrete composite box girders (Fig. 3a) and 110-m continuous steel box girders (Fig. 3b) to cross over the shallow and deep waters, respectively. The superstructure of the bridges comprises two individual $85-\mathrm{m}$ constant depth steel-concrete composite box girders or one single 110-m constant depth orthotropic steel box girders. As shown in Fig. 4 (p.251), the substructure of the bridges consists of large-diameter composite piles, precast pile-caps, and hollow precast pier columns for the $110-\mathrm{m}$ continuous steel box girders or T-head hollow columns for the 85-m composite box girders. The largest combined pile-cap and pier was $40 \mathrm{~m}$ in height and weighed $3000 \mathrm{t}$ (Jing et al., 2015). 


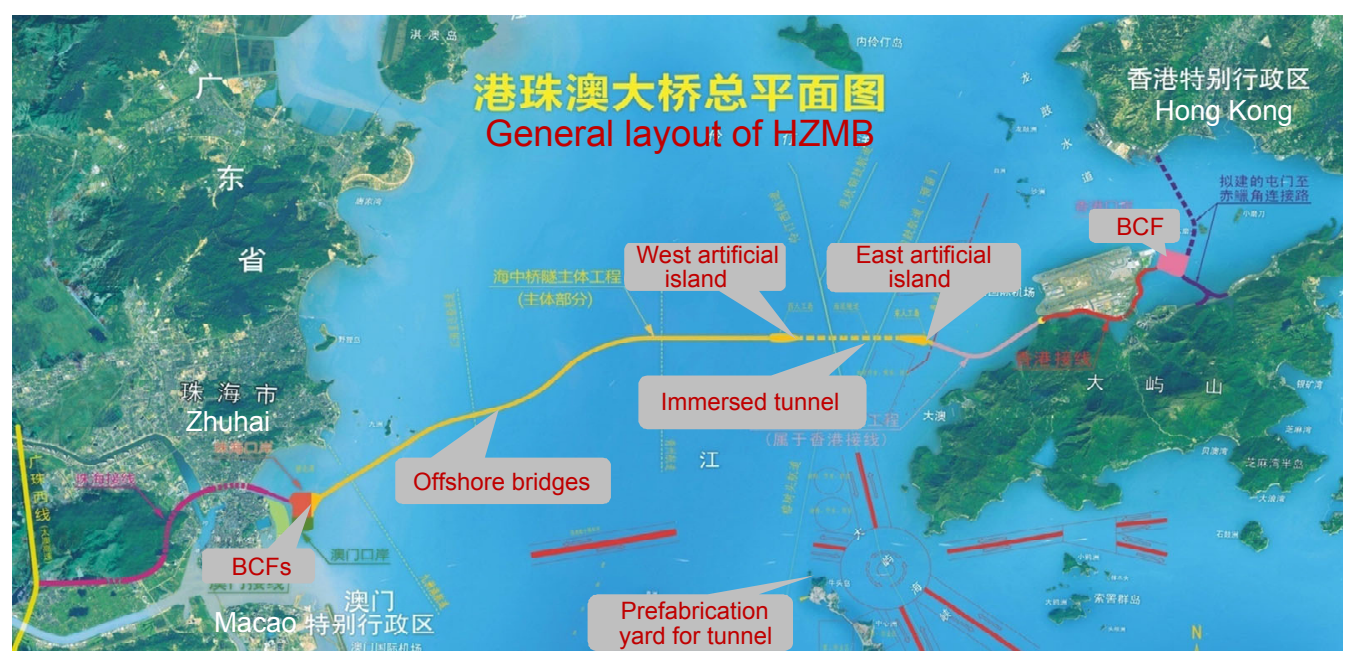

Fig. 1 General layout of the HZMB

BCF: boundary crossing facility

(a)

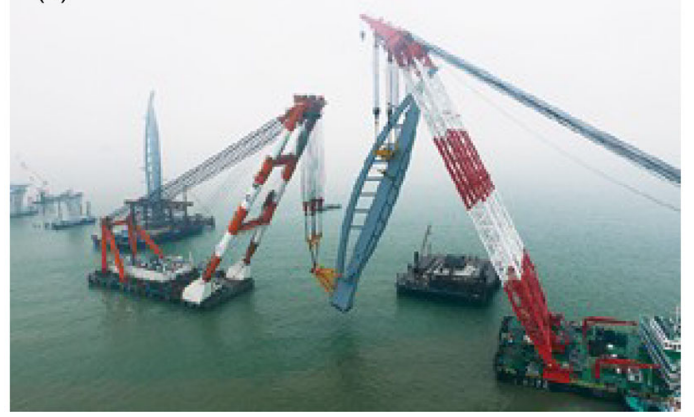

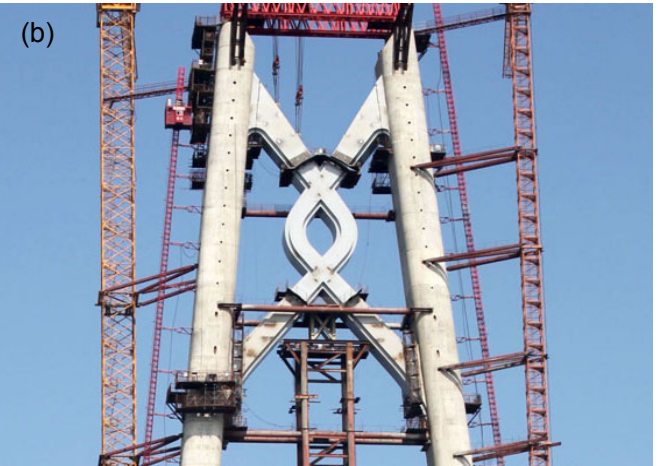

Fig. 2 Towers of the cable-stayed bridges: (a) steel dolphin-shape tower; (b) steel Chinese-Knot-shape bracing
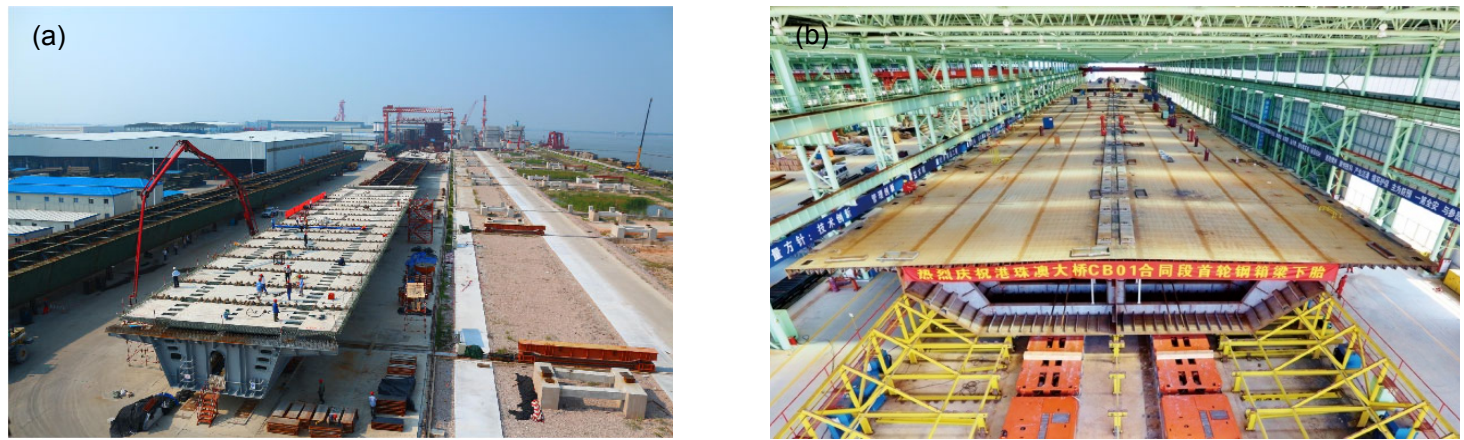

Fig. 3 Superstructure of the bridges on non-navigable waters: (a) 85-m composite girder; (b) 110-m steel box girder

The Main Bridge Project is $22.9 \mathrm{~km}$ in length, about $70 \%$ of which is continuous steel box girders with a uniform span of $6 \times 110 \mathrm{~m}$, as shown in Fig. 5 . The $6 \times 110-\mathrm{m}$ girder is a single-box double-cell steel structure with a uniform cross-section. The $6 \times 110-\mathrm{m}$ girder is longitudinally divided into six span-scale segments at the locations of zero bending moment.
The first segment is the longest $(133 \mathrm{~m})$, the sixth segment is the shortest $(87 \mathrm{~m})$, and the others are all $110 \mathrm{~m}$ in length. The placement scheme of each span-scale segment of the girder is further divided into many small segments, which are fabricated and assembled in factories. Subsequently, the assembled span-scale segments are transported by ships and 
hoisted to the construction positions by a floating crane, as shown in Fig. 6. Finally, they are combined with girth-welding, which is a high efficiency and good safety method for construction. The line shapes and stresses of the girder segments, however, must be strictly controlled during the whole construction phase to ensure the success of welding and positioning (Su and Xie, 2016).
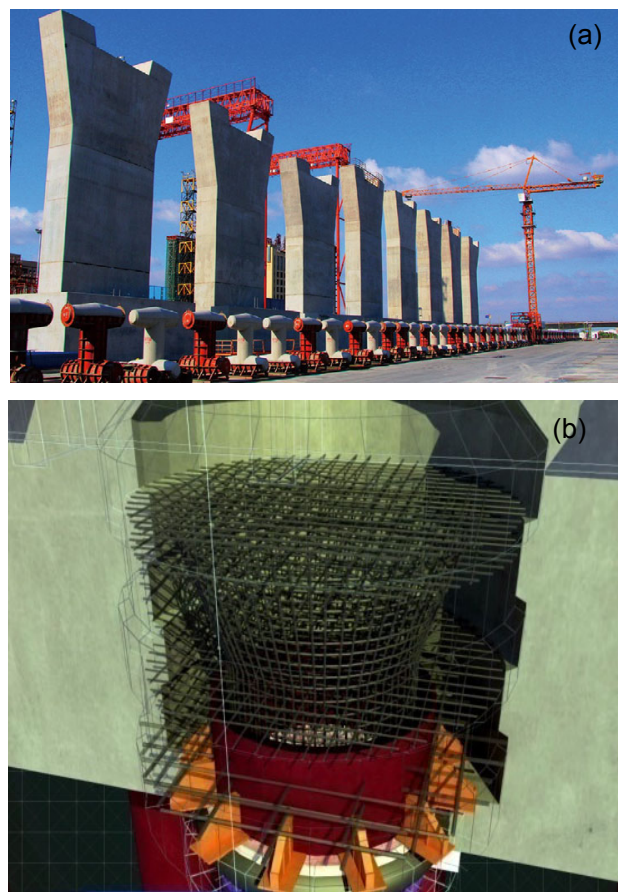

Fig. 4 Substructure of the bridges on non-navigable waters: (a) precast pile-caps and piers; (b) composite pile

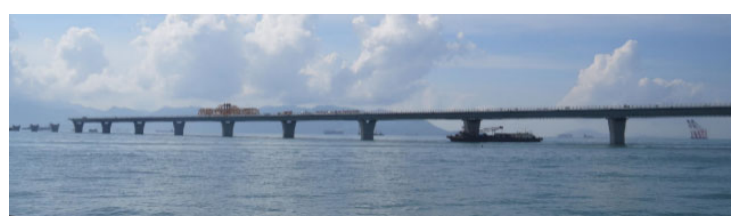

Fig. 5 Side view of the $6 \times 110-m$ steel continuous girder

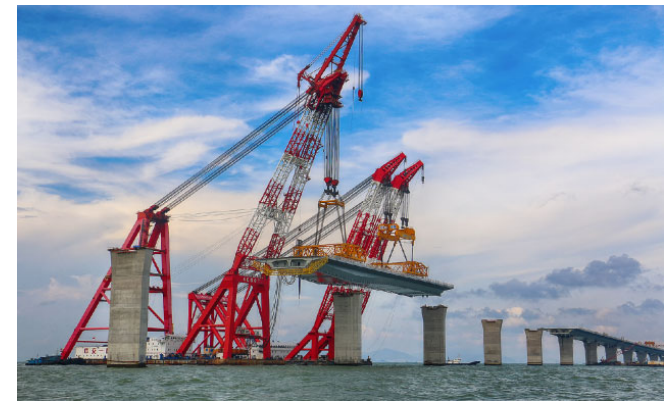

Fig. 6 Hoisting a span-scale girder segment using a floating crane
Unlike most other continuous steel box girder bridges using span-scale girder segment placement in the past, the span-scale girder segments of the HZMB are connected with both bolts and welds to prevent fatigue cracking of bridge deck (Meng et al., 2014b). Consequently, due to the limited adjustable distances of bolt holes, the requirement for the construction accuracy of the HZMB has become even higher than before. The standard width of the girth weld is 6-8 $\mathrm{mm}$, the elevation error of the bridge deck should be controlled within the range from $-10 \mathrm{~mm}$ to $+20 \mathrm{~mm}$, the difference in the width of the girth weld between the top and bottom of the girder segment should not exceed $2 \mathrm{~mm}$, and the offset distance between the center lines of the top and bottom plates of the bearings under the steel box girder should not exceed $20 \mathrm{~mm}$.

Located in an area with high temperature and humidity, the steel box girders and reinforcing bars in concrete structures of the HZMB will be severely affected by corrosion, and many countermeasures have been taken to guarantee the 120-year design service life of these structures. For steel structures, they are externally covered with C5-M level anticorrosion coating, including epoxy zinc-rich primer, epoxy mica iron intermediate paint, and fluorocarbon top coat; the internal faces of the steel structures are covered with thinner anti-corrosion coating; some dehumidification systems are also applied to ensure that the relative humidity of the inside air is under $50 \%$ (Meng et al., 2014a). For reinforced concrete structures, the pile-caps and pier columns are pre-cast as a single unit to avoid un-friendly wet connection works in the sea; some new materials and construction techniques are also applied, such as highperformance stainless steel rebar, epoxy coated rebar, and silane impregnation for concrete (Jing, 2015).

The HZMB has addressed many difficulties on the continuous steel box girders and reinforced concrete structures:

1. The HZMB is in a subtropical zone with high temperatures all year round. Considering the low specific heat capacity and high thermal expansion coefficient of steel, the thermal stresses and deformations during the span-scale steel girder segment placement in the HZMB will significantly affect the performance of the structure and should be strictly controlled during the whole construction. For example, after fabrication in factories, the girder segments 
are placed in some open-air yards waiting for shipment, and a certain number of piers are arranged under the girder segment for temporary support during this period. The temperature gradients in the cross-section of the girder segment will dramatically increase the maximum reaction forces on the temporary piers. This could lead to local buckling in the contact region between the piers and the bottom plate of the girder segment, and thus, the thermal effects during the open-air storage should be carefully considered. Moreover, in the girth-welding of two girder segments, the boundary condition of the structure will be changed from two simply supported beams to one single continuous beam. Since the temperature gradient inevitably exists in the daytime along the cross-section of the girder segment during this process, the temperature gradient disappears at night, and the thermal deflections will not recover because the boundary condition of the structure has been changed. Further, both the uniform temperature changes and temperature gradients will change the length of the girder segments, significantly affecting the positions of the top bearing plates and the performance of bearings. The thermal effects during these processes, therefore, must all be analyzed and controlled.

2. During the span-scale girder segment placement of the steel girders, predicting structural performance and controlling the construction state are usually performed based on the simulation with the finite element method (FEM), and the accuracy of simulation will directly affect the quality, safety, and efficiency of the construction. For the FEM simulation analysis of continuous steel box girder bridges, beam elements are the most popular used elements. There, however, are usually some obvious shear deformations and shear lag effects in a thin-walled steel box girder. Various methods have been proposed to avoid them and improve the general applicability of the beam elements. Nevertheless, these 1D beam elements cannot comprehensively reflect the geometrical and mechanical characteristics of real structures. For the analysis of more complex structures, 3D solid or plate elements are more suitable options. They, however, will always add numerous degrees of freedom into the model when analyzing complex structures, and thus, the computational efficiency will be significantly reduced.
3. Many anti-corrosion measures have been taken for the reinforced concrete structures in the HZMB; nevertheless, the corrosion of reinforcing bars in concrete will not be completely prevented. Once the reinforcing bars in concrete structures are corroded, according to the tension-stiffening mechanism of reinforced concrete, some slip will occur between the reinforcement and concrete. That may seriously influence the development of the deflection. The reduction of the cross-section of the reinforcement due to corrosion also reduces the load capacity of the reinforced concrete structures and affects the safety of the whole project. Consequently, a new numerical method to simulate the structural behaviors of the reinforced concrete considering the corrosion of the reinforcing bars should be developed.

In this special feature, we invited leading scientists in the field to share their expertise and perspectives. The collected papers cover various topics on construction techniques of steel box girders and the numerical method to analyze the structural behavior of reinforced concrete in terms of durability, and the ones mentioned above are including: control measures for thermal effects during the span-scale girder segment placement of a continuous steel box girder bridge, refined analysis and construction parameter calculation of the continuous steel box girder bridge with long cantilevered girder segments during span-scale girder segment placement, and a new numerical method of simulating structural behaviors of reinforced concrete considering the corrosion effects on the reinforcing bars.

Wang et al. (2020a) selected a $6 \times 110-m$ steel box girder in the HZMB, established the finite element analysis model of the girder for its span-scale girder segment placement based on the field-measured temperatures. They studied the thermal effects throughout the construction process of the sample girder, including the thermal effects during the open-air storage, in the boundary condition change due to girth-welding, and in determining pre-set distances for bearings. Some control measures for the thermal effects are proposed, and they were verified by their field applications in the HZMB.

Wang et al. (2020b) applied the spatial augmented finite element method (A-FEM) to analyze the entire placement process of the span-scale girder 
segments for a continuous steel box girder bridge. In the analysis, the degenerated plate elements, which are created by introducing the assumptions of the plate into the $3 \mathrm{D}$ iso-parametric elements, were adopted to comprehensively obtain the geometric and mechanical characteristics of the structure. Based on the A-FEM and degenerated plate elements, the structural responses during the entire placement process of the span-scale girder segments for a real girder were refined, and some formulas were proposed to determine the construction parameters. Finally, when applied in the construction of the continuous steel box girder, the proposed method successfully controlled the construction errors during the entire construction.

Feng et al. (2020) proposed a partial-interaction segmental approach to determine the load-deflection behavior of corroded reinforced concrete structures. By simulating the tension-stiffening mechanism of reinforced concrete, it allows the slip occurrence between the reinforcement and concrete. Different from the traditional strain-based moment-curvature approach, the displacement-based segmental approach directly simulates the deflection development after cracking of concrete with increasing load. By introducing the corrosion of reinforcement, the segmental approach shows the trend of load capacity changing with corrosion level of reinforcement. With provided load-deflection curves collected from tests or measured in practice, the segmental approach could be applied to evaluate the global corrosion level of reinforcement by trial and error procedures. Meanwhile, the segmental approach could be extended to simulate other structures such as composite structures by changing the material properties and bond-slip properties. It also could be applied into the analysis of members like bridge piers by replacing the boundary conditions. For the structures that tend to be easily deteriorated by corrosion due to the environment effects, the presented approach also provides the detailed procedures to simulate structural behavior affected by corrosion.

We believe this special feature will provide a unique opportunity for researchers to present and discuss recent advances in construction control of the placement of span-scale girder segments of continuous steel box girders. The interaction of fundamental science and engineering application will be specifi- cally promoted by the high quality of the technical and scientific standards of the papers. We sincerely hope this special feature will move the research frontier forward and improve the understanding of construction control measures in the full-span erection of continuous steel box girders.

\section{References}

Feng Q, Wang GN, Zhang YP, et al., 2020. Numerical simulation of partial-interaction load-deflection behavior of corroded reinforced concrete beams based on a segmental approach and evaluation of reinforcement corrosion level. Journal of Zhejiang University-SCIENCE A (Applied Physics \& Engineering), 21(4):280-293. https://doi.org/10.1631/jzus.A1900616

Gao WB, Zhang MG, Piao L, 2016. Manufacturing techniques for integral steel pylon of river-to-sea ship channel bridge of Hong Kong-Zhuhai-Macao Bridge. Bridge Construction, 46(2):7-12 (in Chinese).

Hussain N, Wong C, Carter M, et al., 2011. Hong Kong Zhuhai Macao link. Procedia Engineering, 14:1485-1492. https://doi.org/10.1016/j.proeng.2011.07.187

Jing Q, 2015. Analysis method for deformation of long cantilever continuous steel box girder of Hong Kong-ZhuhaiMacao Bridge. Bridge Construction, 45(2):1-5 (in Chinese).

Jing Q, Su QK, Chen DX, 2015. Construction scheme for embedded pile caps of sea-crossing bridge projects of Hong Kong-Zhuhai-Macao Bridge. World Bridges, 43(2): 29-33 (in Chinese). https://doi.org/10.3969/j.issn.1671-7767.2015.02.008

Meng FC, Liu MH, Wu WS, et al., 2014a. The design philosophy and bridge's technical innovation of Hong KongZhuhai-Macao Bridge. Engineering Sciences, 12(3):4857. https://doi.org/10.3969/j.issn.1672-4178.2014.03.009

Meng FC, Su QK, Bu YZ, et al., 2014b. Optimized design of anti-fatigue for orthotropic steel bridge deck. Highway, (10):1-6 (in Chinese).

$\mathrm{Su} \mathrm{QK}, 2005$. An analysis of special techniques for seacrossing bridge. Journal of Highway and Transportation Research and Development, 22(12):101-104 (in Chinese). https://doi.org/10.3969/j.issn.1002-0268.2005.12.027

Su QK, Xie HB, 2016. Summary of steel bridge construction of Hong Kong-Zhuhai-Macao Bridge. China Journal of Highway and Transport, 29(12):1-9 (in Chinese). https://doi.org/10.19721/j.cnki.1001-7372.2016.12.001

Wang JF, Zhang JT, Yang ZX, et al., 2020a. Control measures for thermal effects during placement of span-scale girder segments on continuous steel box girder bridges. Journal of Zhejiang University-SCIENCE A (Applied Physics \& Engineering), 21(4):255-267. https://doi.org/10.1631/jzus.A1900310

Wang JF, Wu TM, Zhang JT, et al., 2020b. Refined analysis 
and construction parameter calculation for full-span erection of the continuous steel box girder bridge with long cantilevers. Journal of Zhejiang UniversitySCIENCE A (Applied Physics \& Engineering), 21(4): 268-279.

https://doi.org/10.1631/jzus.A1900322

Zhang JW, Zhu YL, 2012. Project management planning for construction of Hong Kong-Zhuhai-Macao Bridge (HZMB) Main Bridge Project. Highway, (3):143-147 (in Chinese).

https://doi.org/10.3969/j.issn.0451-0712.2012.03.033

Zhang JW, Zhu YL, 2018. Complexity management: management thinking innovation and practice in Hong KongZhuhai-Macao Bridge main-body engineering. Journal of Systems \& Management, 27(1):186-191 (in Chinese). https://doi.org/10.3969/j.issn.1005-2542.2018.01.022

Zhu YL, Lin M, Meng FC, et al., 2019. Engineering achievements: the Hong Kong-Zhuhai-Macao Bridge. Engineering, 5(1):10-14.

https://doi.org/10.1016/j.eng.2018.11.002

\section{中文概要}

\section{题 目: 港珠澳大桥主桥工程中的连续钢箱梁和钢筋混凝} 土结构

概 要: 作为目前世界上最长的跨海公路桥梁工程, 港珠 澳大桥在设计和施工中遇到了诸多难题, 但它们 都被一一克服; 在此积累的经验非常值得国内外 同行借鉴。为此, 针对港珠澳大桥主体桥梁工程 中连续钢箱梁的施工全过程的温度效应控制、结 构性能预测和施工状态控制及钢筋混凝土结构 中钢筋锈蚀对结构承载力的影响, 本专辑邀请了 直接参与到港珠澳大桥建设的科研人员和工程 管理人员来分享他们的研究成果和观点, 希望能 帮助读者了解相关研究工作并促进研究人员开 展讨论, 以推进该领域的基础研究和技术创新。

关键词: 港珠澳大桥; 连续钢箱梁; 施工控制; 钢筋混凝 土结构; 钢筋锈蚀 